\title{
A ATUALIDADE DA TEORIA CRÍTICA NO BRASIL: 0 EXEMPLO DA INDÚSTRIA CULTURAL
}

Rodrigo Duarte ${ }^{1}$

RESUMO: Este artigo, tradução ligeiramente adaptada, de uma palestra proferida no evento "La actualidad de la Teoría Crítica", realizado no Centro de Ciencias Humanas y Sociales del CSIC (Madrid) em 5 de novembro de 2010, aborda a recepção da Teoria Crítica no Brasil em suas especificidades. Com esse objetivo, são considerados três momentos para o desenvolvimento dessa explanação: (i) apresentação de um relato do processo de desenvolvimento da recepção da Teoria Crítica no Brasil, no que denomino suas duas fases: pré-acadêmica e acadêmica; (ii) delimitação de um conceito de atualidade que esteja de acordo com os princípios da própria Teoria Crítica; e, por fim, (iii) partindo do conceito de indústria cultural, esboço das conclusões que a aplicação de um conceito crítico de atualidade ao processo de recepção da Teoria Crítica no Brasil poderiam oferecer a uma consideração mais imediata.

PALAVRAS-CHAVE: Teoria Crítica; Atualidade; Indústria Cultural.

ABSTRACT: This paper, a slightly modified translation of a lecture pronounced at the event "La actualidad de la 
Teoría Crítica", held at the Centro de Ciencias Humanas y Sociales del CSIC (Madrid) on November 5, 2010, approaches the reception of the Critical Theory in Brazil in its own peculiarities. For this purpose, three stages in the development of this explanation are considered: (i) a report of the development process of the reception of Critical Theory in Brazil in what I call its two phases: the preacademic and the academic; (ii) establishment of a concept of actuality which is itself in accordance with the principles of Critical Theory; and, finally, (iii) starting from the concept of Culture Industry, an outline of the conclusions the application of a critical concept of actuality to Critical Theory reception process in Brazil could offer to a more immediate consideration.

KEYWORDS: Critical Theory; actuality; Culture Industry. 


\section{INTRODUÇÃO}

Falar da atualidade da Teoria Crítica na Iberoamérica - como proposto inicialmente pelos colegas espanhóis ${ }^{2}$ - não é fácil por várias razões. A primeira delas é que existem realidades muito distintas nos diversos países que compõem esse grupo, inclusive até a própria diferença de idioma entre o Brasil, onde se fala o português, e os outros países que são hispanófonos. Ademais, existem situações econômicas também muito diferentes, com níveis de industrialização e de desenvolvimento urbano muito díspares nos diversos países iberoamericanos.

Outra dificuldade é de natureza eminentemente conceitual: reside no próprio conceito de atualidade, cujo significado comum, de ser a característica de algo "up to date", não ajuda de modo algum da abordagem dessa situação que desejamos compreender melhor. Além disso, nem todos os conceitos filosóficos de atualidade poderiam ser úteis na discussão que pretendemos realizar aqui, de modo que seria necessário estabelecer, ainda que provisoriamente, uma concepção adequada.

Pretendo contornar a primeira dificuldade propondo uma drástica limitação do foco de minha exposição, na medida em que abordarei a recepção da Teoria Crítica no Brasil, observando que, sem dúvida, essa realidade pode não ser radicalmente diversa da de países como Argentina, Chile, México, Venezuela, Colômbia ou Uruguai, ainda que possua algumas especificidades. Posso dizer que conheço bem essa história, pois participei (e participo) muito ativamente de sua fase que denomino "acadêmica", de acordo com a terminologia que explicitarei a seguir. Um breve relato sobre esse processo constitui a primeira sessão de minha apresentação. 
Quanto à questão de precisar melhor o conceito de atualidade adequado à nossa discussão, procuro numa segunda sessão estabelecer, ainda que de modo muito esquemático em virtude da limitação de espaço, uma concepção desse termo que esteja de acordo com os princípios da própria Teoria Crítica.

$\mathrm{Na}$ terceira e última sessão, pretendo esboçar, ainda que muito preliminarmente, as conclusões que a aplicação de um conceito crítico de atualidade ao processo de recepção da Teoria Crítica no Brasil poderiam também oferecer a uma consideração mais imediata, enfocando o conceito de indústria cultural.

\section{UMA BREVE HISTÓRIA}

Para compreender melhor a história da recepção da Teoria Crítica no Brasil, devemos ter em conta ao menos duas fases muito distintas. A primeira pode ser chamada de "fase préacadêmica", marcada pelo evidente predomínio do interesse pelo pensamento de Herbert Marcuse. Este era compreendido como uma "atualização" do marxismo, já que se percebia, intuitivamente, que o materialismo histórico tradicional já não dava conta da nova realidade do capitalismo, a qual já se fazia sentir também num país periférico como o Brasil da década de 60. De suma importância na versão marcuseana da Teoria Crítica, foi a incorporação da psicanálise à crítica social de cunho marxista, a qual permitia compreender melhor os sofisticados mecanismos de manipulação da opinião pública pela cultura de massas. É importante observar que o golpe militar de 1964 não impediu que as editoras - ao menos até o início da década de 1970 - continuassem publicando traduções de obras de Marcuse, embora algumas delas fossem muito deficientes.

A segunda fase da recepção da Teoria Crítica no Brasil pode ser chamada de "acadêmica", uma vez que ocorreu 
principalmente nas universidades, especialmente nas faculdades de letras e ciências humanas. Essa fase se dividiu claramente em duas "subfases": a primeira, a partir do início da década de 1970, estava centrada na apropriação do pensamento de Walter Benjamin, provavelmente porque, no entender dos seus protagonistas, seria relativamente mais fácil ocultar os elementos marxistas de seu pensamento, os quais são, na realidade, muitos e bastante fortes. Além disso, é possível que muitos leitores desse filósofo o leram nesse período menos como um marxista e mais como possível inspiração para um enfoque pós-moderno da cultura e da sociedade. Essa subfase se caracteriza pela maior mobilização do pensamento de Walter Benjamin no âmbito da teoria da literatura e dos estudos culturais do que no da filosofia. É também característico desse período uma certa tendência à polarização entre Benjamin e Adorno, de acordo com a qual aquele seria mais "democrático" e este mais "elitista", assim como se pode observar, por exemplo, no livro de Flávio Kothe, Benjamin e Adorno: confrontos ${ }^{3}$.

Um caso excepcional nessa primeira subfase é o de Roberto Schwarz, o qual, ainda na década de 1970, começou a ler Theodor Adorno, tornando-se, juntamente com José Guilherme Merquior ${ }^{4}$, um dos primeiros leitores do filósofo no Brasil. Porém, uma vez que Schwarz não alimentava pretensões filosóficas, já que tinha como objetivo a aplicação do pensamento de Adorno à compreensão de fenômenos literários (como, por exemplo, a novela de Machado de Assis), seu interesse por esse filósofo não gerou um movimento propriamente dito de recepção do filósofo de Frankfurt, ainda que Schwarz tenha sido pioneiro na leitura de suas obras. A segunda subfase, por sua vez, iniciada em meados da década de 1980, apresenta uma clara tendência à recepção 
filosófica da Teoria Crítica, encabeçada pelo crescente interesse no pensamento de Adorno, ao mesmo tempo em que as investigações sobre Benjamin e também sobre outros expoentes da Escola de Frankfurt, como o já mencionado Marcuse (agora considerado com maior seriedade pela academia) ou Max Horkheimer, seguem chamando a atenção de muitos investigadores, inclusive os mais jovens. A partir do início dos anos 90, começou o crescimento do interesse pelos autores da Teoria Crítica também na Pedagogia e na área das ciências da educação em geral.

Para ilustrar o exposto acima, posso fornecer alguns dados, que todavia não estão totalmente atualizados, e que se referem somente a Theodor Adorno: em princípios de 2010, já haviam sido produzidas algumas centenas de artigos (certamente mais de duzentos e cinquenta), mais de cinco dezenas de dissertações de mestrado e duas dezenas de teses doutorais acerca do pensamento desse filósofo. Os livros sobre Adorno, escritos originalmente em português, já passam de trinta, no começo deste ano. Se supusermos que possa existir a metade dessa quantidade de trabalhos publicados sobre Herbert Marcuse, Walter Benjamin e Max Horkheimer, tais números já fazem do Brasil um dos países em que mais se estuda a Teoria Crítica da Sociedade no mundo, o que é para nós muito significativo. Deve-se acrescentar que, por iniciativa da Editora UNES, desde 2008 estão sendo publicadas traduções de obras do próprio Adorno, num ambicioso projeto que, em dez anos, planeja a publicação de uma coleção de vinte obras do filósofo ${ }^{5}$, além dos numerosos livros desse filósofo já publicados em outras casas editoriais.

Pode não ter passado despercebido que, na lista das publicações da Teoria Crítica no Brasil, não mencionei 
Jürgen Habermas, o que não quer dizer que ele não tenha durante certo tempo despertado um grande interesse nos intelectuais brasileiros: em meados dos 1990, houve um "boom" de publicações sobre seu pensamento; não incluí, porém, os muitos trabalhos que se publicaram no Brasil sobre seu pensamento uma vez que não o considero como um legítimo representante da Teoria Crítica, até porque ele não só não preservou o impulso originário dessa vertente filosófica, como a submeteu a uma implacável crítica na Teoria da ação comunicativa ${ }^{6} \mathrm{e}-$ muito especialmente - no Discurso filosófico da modernidade ${ }^{7}$. Além disso, tais posições de Habermas tiveram um efeito desastroso num possível pensamento crítico sobre a realidade brasileira, já que elas escondiam, por baixo da aparência de modernidade, posturas extremamente conservadoras que se combinavam muito bem com as políticas levadas a cabo pelo governo supostamente socialdemocrata de Fernando Henrique Cardoso, em meados dos anos 1990 e começos da década passada, governo que contava com o apoio das mais atrasadas oligarquias do país, expressas pelo então PFL (Partido da Frente Liberal), que posteriormente mudou seu nome para "Os Democratas" (abreviado na sigla "DEM"), como consequência do fato de que muitos de seus membros estiveram envoltos em grandes escândalos de corrupção e desejavam iludir a opinião pública com uma nova denominação.

\section{UM CONCEITO FILOSÓFICO DE "ATUALIDADE"}

Os dados expostos acima, sugerem a existência de uma significativa demanda pela Teoria Crítica no Brasil, a qual, por sua parte, pode dizer-nos algo sobre a atualidade dessa 
corrente filosófica no país. Porém, não se deveria falar aqui de "atualidade" apenas no sentido empregado pela linguagem comum, que poderia denotar somente algo como a existência de uma "moda" no que concerne à adesão à Teoria Crítica. Além do absurdo de considerar "moda" uma corrente filosófica que submete a uma crítica implacável a cultura de massas incluindo o próprio fenômeno da moda - é preciso ter em mente que os números apresentados, embora significativos são ainda muito modestos para um país com as dimensões do Brasil.

Há, por outro lado, um conceito filosófico de "atualidade" que poderia ser aplicável à recepção da Teoria Crítica no Brasil e, para aprofundar a discussão, seria ainda mais interessante compreender melhor essa concepção a partir do pensamento de algum representante da própria "Escola de Frankfurt". Assim, proponho a consideração, aqui, da abordagem de Theodor Adorno acerca desse conceito em seu texto de juventude "A atualidade da filosofia". Apesar de em 1931 o próprio conceito de Teoria Crítica não estar ainda totalmente formulado, podese dizer que o mencionado texto, na medida em que o jovem Adorno já conhecia muito bem, além de Kant, Hegel e Marx, as posições de seu amigo - e então mentor - Walter Benjamin, constitui um passo importante para o estabelecimento do pensamento frankfurtiano.

Sua principal preocupação, nesse texto, é analisar a situação da filosofia na Alemanha nas primeiras décadas do século vinte, sendo sua primeira constatação a da impossibilidade de seguir acreditando no conceito de uma razão capaz de capturar a totalidade do real, a qual caracterizou o pensamento até, pelo menos, a metade do século precedente. Neste sentido, Adorno acusa a "ontologia fundamental" de Heidegger de ainda pressupor, 
na pergunta pelo ser, a possibilidade de "que o Ser não mais se adeque ao pensamento nem o torne acessível, [de modo] que se pode formular a pergunta pela ideia do existente" . $^{\circ}$ Depois da crise do idealismo, as principais correntes do pensamento enfocam o ente como algo desprovido de qualidades próprias, seja por meio do logicismo, como no neokantismo de Marburg, seja por meio de um tipo de intuição vital, como na Lebensphilosophie de Simmel, ou em uma posição intermediária, como a da Escola do Sudoeste Alemão.

Nesse quadro, a Fenomenologia de Husserl obteve a função de repensar a possibilidade do conhecimento, substituindo, porém, a pretensão a uma objetividade última pela obtenção da contribuição intersubjetiva. Para Adorno, o mérito de Husserl foi o de tornar frutífero o conceito do dado para a investigação das relações entre razão e realidade: "O descobrimento realmente produtivo de Husserl - mais importante que o método da 'intuição da essência', que causa um maior efeito externo - foi ter reconhecido e tornado frutífero o conceito do dado irredutível, tal como o haviam configurado as orientações positivistas, em toda a sua significação para o problema fundamental das relações entre razão e realidade" 9 .

Deve-se tomar nota de que, nas fases posteriores do pensamento de Adorno, uma crítica a esse momento idealista na Fenomenologia foi muito importante para a definição, ainda que negativa, de um conceito filosófico de atualidade. Neste caso, Adorno atribui, em Sobre a metacrítica da teoria do conhecimento, a um sociólogo inspirado por Husserl, o erro de proclamar a impossibilidade da sociedade sem classes em virtude da "in-atualidade" das consciências no tocante à realidade empírica. De acordo com esse sociólogo, 
a sociedade sem classes pressuporia uma completa atualidade das consciências, o que não seria possível tendo em vista o perspectivismo da Wesenschau. Dessa premissa, a conclusão - segundo Adorno, tão apressada quanto equivocada - seria exatamente a impossibilidade de uma desalienação completa do sujeito, condenado, portanto, a uma irrevogável "in-atualidade”. Por esse tipo de equívoco, pelo qual Adorno responsabiliza também o próprio Husserl, ele declara que "o conteúdo propriamente reacionário da Fenomenologia é seu ódio contra a 'atualidade"'10. Porém, na construção do primeiro conceito de atualidade, ainda não tomado de modo explícito na discussão sobre a reificação, é importante, como se anuncia desde o início do ensaio de Adorno, a contribuição crítica do pensamento de Heidegger (não tão desvinculado do de Husserl como a posteridade os tem considerado). Contrariamente à auto-compreensão da ontologia fundamental, Adorno assinala que não se trata de investigar o ser em sua objetividade sendo inegáveis, porém, os momentos de retorno da subjetividade a si mesma. Daqui se originou, segundo Adorno, sua proximidade com a filosofia existencial de Kierkegaard, cujo corolário desse movimento seria o estabelecimento, por parte de Heidegger, da chamada "metafísica da morte". No agudo juízo de Adorno, por mais que a Fenomenologia - e principalmente a ontologia fundamental - pretendesse combater o subjetivismo da Lebensphilosophie, afora o aspecto da morte não existiria uma diferença tão grande entre elas: "a transcendência da morte em Simmel só se diferencia da de Heidegger por conservar categorias psicológicas a que Heidegger nomeia categorias ontológicas, sem que no assunto mesmo por exemplo, na análise do fenômeno da angústia - se possa encontrar um meio seguro para distingui-las"11. 
A discussão de Adorno sobre o cenário da filosofia alemã no início do século vinte culmina exatamente com uma definição operacional da "atualidade", a qual nos pode ser útil na consideração da situação da Teoria Crítica especialmente no Brasil. A definição é a seguinte: "Não se entende por atualidade uma vaga 'expiração' ou não expiração baseada em ideias arbitrárias sobre a situação espiritual em geral, mas, ao invés, no seguinte: se existe ainda alguma adequação entre as questões filosóficas e a possibilidade de respondê-las, após os progressos dos últimos grandes esforços nessa direção; se, a rigor, o resultado da história filosófica mais recente não é a impossibilidade por princípio de uma resposta para as perguntas filosóficas cardeais" ${ }^{12}$.

Por meio desse tipo de demanda para a filosofia, Adorno chega à ideia de uma "filosofia interpretativa" (detutende Philosophie) a qual apresenta certa afinidade com o materialismo, na medida em que concebe o real como inteiramente desprovido de intencionalidade e, portanto, demandante de um tio de elucidação também doadora de sentido. Os modelos preexistentes para uma filosofia desta ordem são tanto a psicanálise, com sua ideia original de "interpretação dos sonhos", como a análise da mercadoria levada a cabo pela crítica da economia política de Marx. Nesse aspecto particular, já nos encontramos em pleno território da Teoria Crítica da Sociedade, pois a leitura que Adorno faz da forma mercadoria tem como fundo a discussão kantiana sobre a coisa em si, ainda que seja para negar sua vigência no cenário da filosofia contemporânea:

Mas seria possível que, numa construção satisfatória da forma mercadoria, o problema da coisa em si se esvaísse: que a figura histórica da forma mercadoria e do valor de troca, como uma fonte de luz, deixasse a descoberto a configuração de uma realidade posterior de cujo sentido último se esforçava em vão o problema 
da coisa em si, posto não haver nenhum sentido último que fosse separável de sua manifestação histórica, primeira e única ${ }^{13}$.

\section{A POSSÍVEL APLICAÇÃO DO CONCEITO DE ATUALIDADE EXTRAÍDO DA SITUAÇÃO BRASILEIRA: 0 EXEMPLO DA INDÚSTRIA CULTURAL}

Ainda que possamos responder negativamente à mencionada pergunta sobre a possibilidade de dar resposta a "perguntas filosóficas cardeais", tal como a planejou Adorno no ensaio "A atualidade da filosofia", é de fato passível de defesa que algumas questões (ainda que não "cardeais") sobre uma determinada sociedade podem e devem ter respostas filosóficas. Ao meu modo de ver, este tem sido o caso de muitos países latino-americanos, e uma das ideias mais caras à esta exposição é a de que a Teoria Crítica tem oferecido uma contribuição significativa para que as respostas filosóficas às questões candentes dessas sociedades não estejam marcadas nem pelo objetivismo meramente cientificista, por um lado, nem por um subjetivismo resignado - ainda que travestido de ontologismo fundamental - , por outro.

Essa foi a marca registrada da recepção da Teoria Crítica no Brasil desde seu primeiro momento, o qual, como se afirmou acima, voltava sua atenção à obra de Herbert Marcuse como possível guia na renovação política da esquerda. Também no primeiro período da segunda fase - "acadêmica" - dessa recepção, é inegável a intenção de compreender criticamente a realidade brasileira por parte de seus leitores, já que a inspiração benjaminiana possibilitou acessos inusitados, por exemplo, à obra literária de escritores como Guimarães Rosa.

De qualquer forma, o maior desafio interpretativo sobre a influência da Teoria Crítica no Brasil está no crescente interesse 
pelo pensamento de Adorno, a partir de meados dos anos 80 e, de modo muito especial, depois de 1990. Uma possível razão para esse fenômeno foi o fim do regime militar em 1985, depois do qual a situação política se tornou muito mais complexa e, portanto, de compreensão muito mais difícil. Mesmo antes do golpe militar de 1964 não havia dúvidas para a esquerda de que a direita - especialmente a militante - era um mal em si mesmo, a ser combatido. Porém, depois do fim da ditadura, se tornou evidente que a polarização anterior escamoteava o fato de que alguns políticos civis que apoiavam a luta contra os militares não só eram também direitistas como também, em certos casos, eram tão corruptos como os antigos caudilhos que governaram o país de 1964 a 1985. É possível que, por trás dessas circunstâncias, o recurso ao refinado pensamento social de Adorno se apresentara para um grande número de pessoas críticas como altamente adequado para abordar a nova situação.

É claro que é muito difícil demonstrar cabalmente o que afirmei agora, ainda mais tendo em conta as dimensões deste trabalho, porém talvez possa ilustrar este caso, à semelhança do dito por Adorno sobre o contorno de uma forma como a da mercadoria na nomeação de outrora, com o tema da cultura de massas. Faz parte do mencionado refinamento da filosofia social de Adorno o fato de que ele foi capaz de mostrar a infiltração dos elementos estéticos na política e na sociedade contemporâneas como muito poucos, de modo que se tornou evidente que a dominação passa hoje por uma sedução de amplas camadas da população por meio de motivos sensoriais. Deste modo, a centralidade das discussões sobre a indústria cultural em toda a obra de Adorno pode explicar, ainda que parcialmente, o grande interesse por seu pensamento no Brasil.

Isso é assim devido ao fato de que desde os anos 30 existe no país uma cultura de massas que inclui tanto o cinema quanto a 
rádio comercial, assim como os outros tipos de dispositivos da chamada indústria cultural. Se, por um lado, não é equivocado dizer que essa seja filha de uma ditadura, já que foi no tempo do "Estado Novo", sob Getúlio Vargas, que começou seu primeiro grande desenvolvimento, existe, por outro lado, uma característica da indústria cultural que a torna especialmente adequada para os contextos de vigência plena em uma democracia formal, burguesa, na qual as massas devem escolher os governantes que interessam ao sistema econômico (com suas políticas hostís aos interesses da maioria), pensando, por outro lado, estarem elegendo livremente os candidatos que lhes parecem mais adequados. É exatamente por isso que a indústria cultural é hoje tão importante para a manutenção do status quo em todo o mundo e especialmente nos países ocidentais, para os quais interessa ostentar a maior liberdade possível, mesmo sabendose que, no "mundo administrado", do qual especialmente eles fazem parte, isso não passa de uma aparência ilusória.

É possível que, apesar do fato de que, nas duas ditaduras vividas no Brasil no século vinte, os meios de comunicação de massas tenham desempenhado um papel importante, foi somente depois de 1985 que as condições se mostraram suficientemente maduras para o pleno desenvolvimento de um sistema como o da indústria cultural, quando o país já estava suficientemente industrializado e moderno, por um lado, e consolidara uma democracia formal, por outro. Pode ser que, nesse contexto, as enormes proporções de alguns agentes dessa indústria cultural brasileira, como por exemplo a Rede Globo de televisão, que é uma das maiores emissoras privadas de TV do mundo, tenham estimulado a um número considerável de intelectuais a se aproximarem do pensamento de Adorno, na medida em que nele reconheceram o crítico da cultura de massas por excelência. 
Esse processo de apropriação da teoria crítica da indústria cultural para a compreensão da situação brasileira ocorreu de modo gradual, pois, talvez pelo fato de que a recepção de Adorno (e por conseguinte dos outros filósofos da Teoria Crítica) no Brasil se deu no meio acadêmico, inicialmente os artigos, livros, teses e dissertações produzidos sobre o assunto estavam marcados principalmente por um tipo de aprendizagem de sua filosofia densa e obscura, na qual não havia muita novidade com relação aos trabalhos produzidos nos países europeus ou norte-americanos. Posteriormente, porém, enquanto as pesquisas sobre Adorno já não se limitavam aos âmbitos da filosofia e da pedagogia, estendendo-se também aos campos da sociologia, ciência do esporte, teologia, musicologia, teoria da literatura, etc., pode-se observar uma clara tendência de seus autores a pretenderem abordar reflexivamente os diferentes aspectos da realidade brasileira com as ferramentas da Teoria Crítica da Sociedade.

Outra característica interessante da recepção da Teoria Crítica no Brasil, no sentido do estabelecimento de sua "atualidade", e o que chamo sua progressiva "capilarização": a tendência inicial de ela ter sido recebida somente nas universidades mais tradicionais das maiores cidades do país está sendo superada, no sentido de que hoje ela é influente não apenas no sul e no sudeste, como também no norte e nordeste do país, tradicionalmente mais carentes em termos econômicos. Dado que essas regiões, por outro lado, são muito ricas em termos da cultura popular "autêntica", é possível que, em algum momento deste processo, surjam abordagens muito interessantes da crítica cultural, tendo em conta modelos alternativos ao da 
cultura erudita europeia, que serviu de base para a crítica adorniana, por exemplo.

Considerando o exposto, poder-se-ia dizer, para concluir, que o processo descrito de recepção da Teoria Critica no Brasil, mostra uma atitude intelectual não apenas receptiva, mas que apresenta uma atividade, a qual juntamente com o desenvolvimento dessa corrente de pensamento que ocorrem em outras partes do globo, prova o alcance e a vigência de um princípio teórico caro à Teoria Crítica, a saber, a historicidade dos conceitos.

\section{NOTAS}

${ }^{1}$ Professor titular do Departamento de Filosofia da Universidade Federal de Minas Gerais (UFMG). Doutor em Filosofia pela Universität Gesamthochschule Kassel. Realizou estágios de pós-doutoramento na University of California at Berkeley (1997), na Universität Bauhaus de Weimar (2000) e na Hochschule Mannheim (2011). De maio de 2006 a outubro de 2014, foi presidente da Associação Brasileira de Estética (ABRE). Dentre suas publicações no Brasil e no exterior, destacam-se os livros: "'Mímesis e Racionalidade. A concepção de domínio da Natureza em Theodor W. Adorno” (1993), “Teoria Crítica da Indústria Cultural” (2003), "Dizer o que não se deixa dizer. Para uma filosofia da expressão" (2008), "Deplatzierungen. Aufsätze zur Ästhetik und kritischer Theorie" (2009), "Pós-história de Vilém Flusser. Gênese-anatomiadesdobramentos"(2012) e "Varia Aesthetica. Ensaios sobre arte e sociedade" (2014).

${ }^{2}$ A versão original deste texto, "La actualidad dela Teoria Critica en Iberoamérica en el ejemplo de Brasil", é uma palestra proferida por mim no evento "La actualidad de la Teoría Crítica", realizado no Centro de Ciencias Humanas y Sociales del CSIC (Madrid) em 5 de novembro de 2010. O texto original se encontra na página: http://www.setcrit.net/la-actualidad-de-la-teoria-criticaen-iberoamerica-en-el-ejemplo-de-brasil/ (acesso em 12/03/2015) e a presente 
tradução foi feita por Charliston Pablo do Nascimento e revisada/adaptada pelo autor do artigo.

${ }^{3}$ Flávio Kothe, Benjamin e Adorno: Confrontos. São Paulo: Editora Ática, 1978. ${ }^{4}$ Ver meu artigo "O caso Merquior", Constelaciones. Revista de Teoría Crítica, n.1, 2009, pp.36-50: http://constelaciones-rtc.net/01/01_03.pdf.

${ }_{5}^{5}$ Já foram publicados nessa coleção os seguintes volumes: "As estrelas descem à terra", "Introdução à Sociologia", "Berg", "Kierkegaard", "Introdução à sociologia da música", "Correspondência" e "Três estudos sobre Hegel". Mais informações sobre essa coleção podem ser encontradas na página: http:// www.editoraunesp.com.br/colecao-assunto/1, adorno (acesso em 11/04/15). ${ }^{6} J u ̈ r g e n ~ H a b e r m a s$, Theorie des kommunikativen Handelns. Frankfurt am Main, Suhrkamp Verlag, 1988 (2 volumes).

${ }^{7}$ Jürgen Habermas, Der philosophische Diskurs der Moderne. Zwölf Vorlesungen. Frankfurt am Main, Suhrkamp Verlag, 1988.

${ }^{8}$ Theodor W. Adorno, Die Aktualität der Philosophie, In: Gesammelte Schriften 1, Frankfurt am Main, Suhrkamp Verlag, p.325.

${ }^{9}$ Ibidem, p.327.

${ }^{10}$ Theodor W. Adorno, Gesammelte Schriften 5: Zur Metakritik der Erkenntnistheorie. Drei Studien zu Hegel. p. 222: „Der eigentlich reaktionäre Gehalt der Phänomenologie ist ihr $\mathrm{Haß}$ gegen die »Aktualität «". ${ }^{11}$ Theodor W. Adorno, Die Aktualität der Philosophie, op.cit., p. 330.

${ }^{12}$ Ibidem, p. 331.

${ }^{13}$ Ibidem, p. 337. 


\section{REFERÊNCIAS}

ADORNO T. Die Aktualität der Philosophie. In: Gesammelte Schriften 1, Frankfurt am Main: Suhrkamp Verlag.

ADORNO, T. Gesammelte Schriften 5: Zur Metakritik der Erkenntnistheorie. Drei Studien zu Hegel. Frankfurt am Main: Suhrkamp Verlag.

DUARTE, R. "O caso Merquior". Constelaciones, Revista de Teoría Crítica, n.1, 2009, pp.36-50. Disponível em: $<<\mathrm{http} / / /$ constelaciones-rtc.net/01/01_03.pdf >>.

KOTHE, F. Benjamin e Adorno: Confrontos. São Paulo: Ática, 1978.

HABERMAS, J. Theorie des kommunikativen Handelns. Frankfurt am Main: Suhrkamp Verlag, 1988 (2 volumes).

HABERMAS, J. Der philosophische Diskurs der Moderne. Zwölf Vorlesungen. Frankfurt am Main: Suhrkamp Verlag, 1988. 